\title{
PENGOLAHAN AIR LIMBAH INDUSTRI KECIL PELAPISAN LOGAM
}

\author{
Oleh : \\ Satmoko Yudo dan Nusa Idaman Said
}

Kelompok Teknologi Pengelolaan Air Bersih dan Limbah Cair, Pusat Pengkajian dan Penerapan Teknologi Lingkungan, BPPT.

\begin{abstract}
Water pollution in Jakarta area, especially river and shallow groundwater, had become a very serious problem. Pollution problem caused by small industrial activities had not been got attetion. Some activities, which often cause water pollution problem, were wastewater from electroplating small industry. This wastewater was one of the most potential pollutant sources, because it contains high concentration of heavy metal pollutant such as $\mathrm{Fe}, \mathrm{Ni}, \mathrm{Zn}, \mathrm{Cr}$, ect. To anticipate its negative effect to the environment and social life, it needs to provide a technical standard plan to manage wastewater treatment plant, especially of electroplating small industries. The purpose of these activities is to do the assessment and application of wastewater treatment technology of electroplating small industry. The target is to get design engineering and pilot plant of wastewater treatment technology for electroplating small industry.
\end{abstract}

Kata kunci : Pencemaran logam berat, Pengolahan limbah cair industri kecil pelapisan logam.

\section{PENDAHULUAN}

\subsection{Latar Belakang}

Sejak awal tahun 1970-an berbagai macam industri seperti industri-industri permesinan, perakitan kendaraan bermotor, alatalat elektronika, sepeda, serta barang-barang logam lain telah tumbuh dan berkembang pesat.

Beberapa diantara industri-industri tersebut telah memiliki unit proses pelapisan listrik sendiri dan mampu menghasilkan sendiri barang-barang secara lengkap.

Untuk melayani kebutuhan jasa bagi industri-industri yang tidak memiliki unit pelapisan listrik sendiri, tumbuhlah industri jasa pelapisan listrik di berbagai tempat di Indonesia. Umumnya merupakan industri kecil atau industri rumah dan menurut hasil survey Lembaga Metallurgi Nasional - LIPI di Bandung jumlahnya mencapai 250 buah.

Industri pelapisan listrik yang menggunakan beraneka ragam bahan kimia untuk prosesnya antara lain berbagai asam, basa dan senyawa-senyawa kimia seperti khromat, sianida, khlorida, posfat, dan lain-lain, menghasilkan bahan buangan yang berupa padatan, cairan maupun gas yang berbahaya.

Walaupun jumlah bahan limbah dari industri pelapisan listrik ini tidak sebanyak yang dihasilkan industri lain, namun karena sifatnya yang sangat beracun maka bahan buangan yang sedikit ini amat berbahaya bagi manusia serta dapat mengancam kelestarian kehidupan alam sekelilingnya, oleh karena itu sebelum dibuang keluar pabrik harus diolah terlebih dahulu. Sebagai gambaran dapat disebutkan komposisi bahan-bahan kimia berbahaya yang ada dalam air buangan dari industri pelapisan logam misalnya tembaga ppm, seng $15 \mathrm{ppm}$, kadmium 15 ppm, nikel 25 ppm, khrom 50 ppm, sulfat 75 ppm.

Khususnya bagi industri besar usaha penanggulangan pencemaran sudah dilakukan, bahkan ada yang sudah memiliki unit pengolahan bahan buangan secara sempurna. Permasalahannya pada kebanyakan industri kecil usaha tersebut masih belum ditangani dengan betul atau usahanya masih terbatas sekali. Berbagai macam teknologi untuk mengolah bahan-bahan buangan kimia telah banyak dikembangkan orang, dari yang paling sederhana dan murah sampai pada yang sangat modern dan mahal, yang mampu menghasilkan produk yang memenuhi standar kualitas lingkungan yang dipersyaratkan.

Salah satu usaha mengatasi permasalahan tersebut di atas, Kelompok Teknologi Pengelolaan Air Bersih dan Limbah Cair, Pusat Pengkajian dan Penerapan Teknologi Lingkungan, TIEML-BPPT melakukan pengkajian dengan membuat pilot-plant pengolahan air limbah industri kecil pelapisan logam. Lokasi pilot plant IPAL ini di CV. Salsabila Electroplating, kelurahan Cilodong, Kodya Depok, Jawa Barat. 


\subsection{Tujuan Penelitian}

Tujuan dari kegiatan ini adalah melakukan pengkajian teknologi pengolahan air limbah industri kecil pelapisan logam, sedangkan sasarannya adalah membuat disain teknis (Design Engineering) Instalasi Pengolahan Air Limbah (IPAL) industri kecil pelapisan logam serta pembuatan Pilot plant IPAL industri kecil pelapisan logam.

\section{$1.3 \quad$ Metodologi}

Metodologi kegiatan adalah sebagai berikut :

\section{a. Survai Lapangan}

Survai ini dilakukan untuk mengetahui keadaan di lapangan mengenai jumlah penduduk yang akan dilayani, kualitas air tanah/ sumur, serta kondisi sosial masyarakatnya.

\section{b. Penentuan Lokasi}

Lokasi prototipe unit alat pengolah air limbah harus ditentukan sedemikian rupa agar didapatkan hasil yang memuaskan, baik ditinjau dari segi teknis maupun estetika. Sedapat mungkin lokasi ditentukan agar mengganggu pemukiman masyarakat setempat.

\section{c. Ketersediaan Bahan dan Peralatan}

Bahan dan peralatan yang diperlukan untuk pembangunan unit pengolahan air limbah diharapkan dapat dengan mudah didapat di pasaran, sehingga dapat memberikan kemudahan dalam pengerjaan pembangunan dan biaya konstruksi dapat ditekan serendah mungkin.

\section{d. Rancangan dan Konstruksi}

Disain unit alat pengolah air limbah dirancang berdasarkan jumlah dan kualitas air baku, serta sesuai dengan ketersediaan lahan yang ada. Prototipe alat pengolah air limbah tersebut tersebut akan dirancang dalam bentuk yang kompak agar pemasangan atau pembangunan serta operasinya mudah, serta diusahakan menggunakan energi sekecil mungkin.

\section{e. Pembangunan Prototipe dan Pengujian Karakteristik Alat}

Setelah prototipe alat pengolah air limbah selesai dibangun, dilakukan pengujian karakteristik alat dan pengujian hasil pengolahan terhadap beberapa parameter sesuai dengan standar kualitas limbah industri logam.

\section{f. Pengoperasian Alat}

Sebelum diserahkan kepada calon pengelola, dilakukan pelatihan pengoperasian alat serta cara perawatan alat kepada calon pengelola agar alat dapat beroperasi dengan baik dan terawat.

\section{TINJAUAN PUSTAKA}

\subsection{Proses Pelapisan Logam}

Prinsip dasar dari pelapisan logam secara listrik adalah penempatan ion logam yang ditambah elektron pada logam yang dilapisi, yang mana ion-ion logam tersebut didapat dari anoda dan eletrolit yang digunakan. Secara eletro kimia prosesnya dapat dilihat pada gambar sebagai berikut :

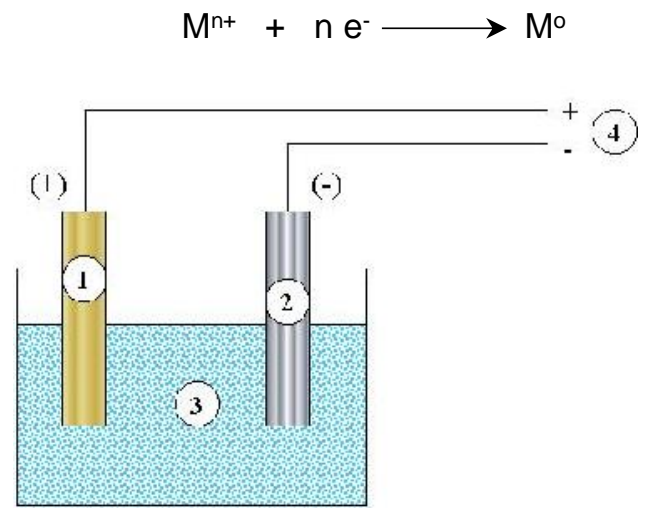

Keterangan :

(1) Anoda (bahan pelapis);

(2) Katoda (benda kerja);

(3) Elektrolit; dan

(4) Sumber arus searah.

\section{Gambar 1 : Skema Pelaksanaan Pelapisan Logam Secara Listrik}

Dengan adanya arus yang mengalir dari sumber maka elektron "dipompa" melalui eletroda positip (anoda) menuju eletroda negatip (katoda). Dan dengan adanya ion-ion logam yang didapat dari eletrolit maka menghasilkan logam yang melapis permukaan logam lain yang dilapis. Oleh karena proses ini adalah proses listrik maka bila terdapat kotoran yang menempel pada permukaan katoda maka elektron dan ion logam yang ada akan terhalang oleh kotoran tersebut sehingga tidak akan ada pelapisan pada tempat yang kotor tersebut.

Proses pelapisan logam secara listrik (Elektroplating) terdiri dari beberapa urutan proses antara lain persiapan bahan yang akan dilapis, pelapisan dan penyelesaian akhir.

\subsubsection{Proses Pelapisan Tembaga}

Proses ini banyak digunakan antara lain untuk memperoleh lapisan pada permukaan logam dengan tujuan sebagai lapisan pelindung, 
meningkatkan penampilan, sebagai lapisan dasar untuk pelapisan selanjutnya, memperoleh lapisan dengan hantar panas dan arus listrik yang baik dan kadang proses ini digunakan juga dalam proses elektro forming.

Bagan alir dari proses secara keseluruhan, dapat dilihat pada Gambar .

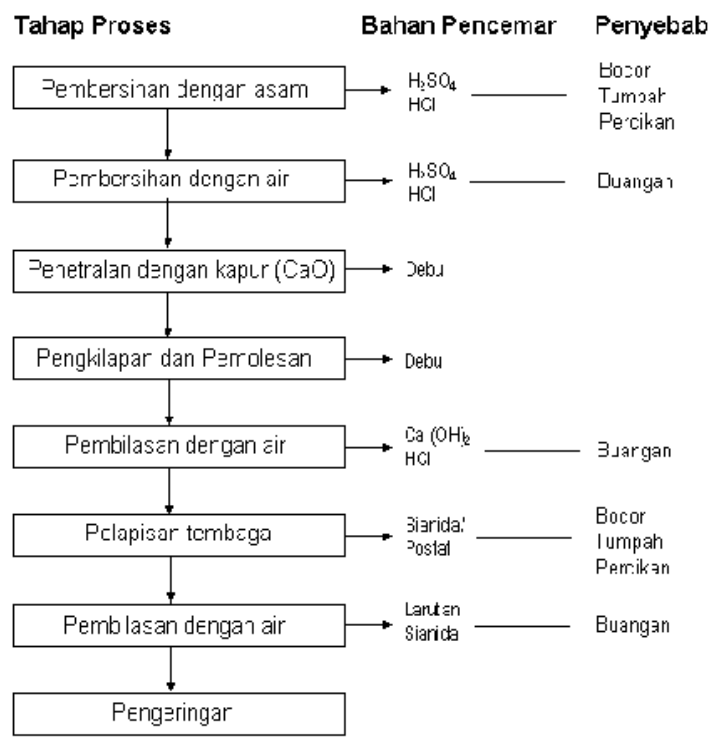

Gambar 2 : Proses pelapisan tembaga serta unsur pencemaran yang dikeluarkan.

Urutan proses pelapisan tembaga tersebut mencakup beberapa tahapan yakni pembersihan, pembilasan air, proses pelapisan tembaga, pembilasan air dan pengeringan.

Proses seperti pada bagan alir tersebut dapat pula berubah-ubah, terutama tergantung dari keadaan dan tingkat kebersihan benda sebelum diproses. Sebelum tahapan tersebut diatas sudah barang tentu dimulai dengan pekerjaan-pekerjaan pemotongan dan proses pembentukan.

Pembersihan dengan asam sering digunakan bilamana benda yang akan dilapisi sudah berkarat. Sedangkan proses pembersihan ini bisa dilalui dan langsung pada tahapan proses pembersihan lemak (degreasing) bagi bendabenda yang belum berkarat atau keadaan yang masih baik. Pemolesan kadang-kadang dilakukan juga setelah pengeringan (proses akhir bilamana dipandang perlu).

\section{a. Proses Pembersihan Lemak (Degreasing)}

Disini benda yang akan diproses cukup dicelup dalam suatu larutan zat-zat organik misalnya Trikhloretilen, alkohol, bensin, deterjen dan sebagainya, yang bertujuan untuk penghilangan lemak (organik); pekerjaan ini dilakukan dalam bak yang terbuat dari baja tahan karat. Lemak ini sangat mengganggu pada proses pelapisan karena mengurangi daya hantar listrik atau mengurangi kontak antara lapisan dengan logam dasarnya. Pembersihan dengan cara ini dapat digolongkan dalam dua katagori yaitu pembersihan yang dilakukan pada keadaan panas dengan pelarut organik yang tidak mudah terbakar dan pembersihan yang dilakukan dalam suhu kamar.

\section{b. Proses Pembersihan Dengan Asam (Pickling)}

Proses pickling adalah pembersihan oksida secara kimiawi melalui pencelupan dalam larutan asam. Lapisan oksida pada permukaan umumnya terdiri dari beberapa ikatan, bagian terluar dan terbanyak adalah $\mathrm{Fe}_{2} \mathrm{O}_{3}$, bagian tengah $\mathrm{Fe}_{3} \mathrm{O}_{4}$ dan bagian lebih dalam lagi dekat logamnya adalah $\mathrm{FeO}$.

Reaksi-reaksi pada saat pembersihan adalah sebagai berikut :

- $\mathrm{Fe}_{2} \mathrm{O}_{3}+2 \mathrm{H}_{2} \mathrm{SO}_{4}+\mathrm{H}_{2} \rightarrow 2 \mathrm{FeSO}_{4}+3 \mathrm{H}_{2} \mathrm{O}$

- $\mathrm{Fe} 3 \mathrm{O} 4+3 \mathrm{H}_{2} \mathrm{SO}_{4}+\mathrm{H}_{2} \rightarrow 3 \mathrm{FeSO}_{4}+4 \mathrm{H}_{2} \mathrm{O}$

- $\mathrm{FeO}+\mathrm{H}_{2} \mathrm{SO}_{4} \rightarrow \mathrm{FeSO}_{4}+\mathrm{H}_{2} \mathrm{O}$

- $\mathrm{Fe}+\mathrm{H}_{2} \mathrm{SO}_{4} \rightarrow \mathrm{FeSO}_{4}+\mathrm{H}_{2}$

Reaksi pickling sebetulnya adalah proses elektro kimia dalam sel galvanis antara logam murni (anoda) dan oksida (katoda). Gas $\mathrm{H}_{2}$ yang mereduksi Ferri Oksida menjadi Ferro Oksida Yang Mudah Larut. Dalam reaksi ini biasa diberikan inhibitor agar reaksi tidak terlalu cepat dan menghasilkan pembersihan permukaan yang merata. Asam yang digunakan untuk pickling ini biasanya asam bisulfat, asam chlorida dan campuran asam-asam lainnya.

Bak untuk pickling biasanya terbuat dari plat baja tahan karat atau plat baja yang dilapis dengan PVC, polipropelene, plastik, karet atau email.

\section{c. Proses Pembilasan}

Biasanya dilakukan dengan air di dalam satu atau beberapa bak yang terbuat dari baja tahan karat. Sistem pembilasan dalam beberapa bak pada umumnya bisa merupakan arah berlawanan antara benda kerja dengan aliran air dari bak satu ke bak lainnya. Pada proses bertahap melalui beberapa bak pada dasarnya dimaksudkan untuk memperoleh pembersih yang efektif atau untuk memperoleh keadaan yang sama dapat juga menggunakan sistem semprot. Baik di dalam proses satu bak atau beberapa bak pada prinsipnya memakai aliran air yang 
mengalir dan menghasilkan air buangan yang terbanyak.

Disain bak merupakan salah satu faktor untuk memperoleh tingkat kebersihan yang tinggi antara lain berkait dengan sistem sirkulasi air di dalam bak dan sistem kesempurnaan air untuk melepaskan kotoran dari permukaan benda dan membawa bersama aliran keluar.

\section{d. Proses Pembersihan Mekanis (Pemolesan)}

Proses pemolesan biasanya dilakukan dengan maksud untuk menghaluskan permukaan atau menghilangkan goresan-goresan. Sebagian kecil dari permukaan logam terbuang dan kehalusan yang diperoleh dengan cara ini kirakira 16 mikron. Hal-hal yang mendapat perhatian dari proses ini adalah mengenai abrasive (obat poles), kain poles (mop), penyenteran dan kesetimbangan kain poles dalam arah radial. Abrasive yang sering digunakan adalah lebih banyak dalam bentuk pasta daripada bentuk cair. Jenisnya kebanyakan terbuat dari partikelpartikel korondum (oksida A1) yang sangat keras yang didapat dari alam. Sedangkan abrasive buatan biasanya karbida silikon. Kehalusan abrasive bermacam-macam yaitu diperoleh dengan proses pengayakan antara 30 sampai 250 mesh, dan bilamana dengan pemisah (silikon) diperoleh 230 sampai 600 mesh. Kain poles kebanyakan terbuat dari kain kanvas, belacu, satyns, laken dan sebagainya.

Jenis abrasive dan kain yang digunakan tergantung daripada jenis logam yang diproses. Proses pemolesan terbatas pada bentuk dan permukaan tertentu sehingga mendapat kesulitan untuk permukaan bagian dalam atau pada ukuran-ukuran yang sangat kecil.

\section{f. Proses Pelapisan}

Pada prinsipnya proses pelapisan ini merupakan proses pengendapan logam secara elektro kimia. Sumber listrik arus searah sudah barang tentu merupakan peralatan pokok. Peralatan sumber arus searah terdiri dari pengubah tegangan tinggi ke tegangan rendah dengan kuat arus searah terdiri dari pengubah tegangan tinggi ke tegangan rendah dengan kuat arus besar, serta alat penyearah (rectifier) yang mengubah arus bolak-balik menjadi arus searah. Barang yang akan dilapisi harus ditempatkan dalam elektrolit sebagai katoda negatip (-). Dengan demikian di sini terjadi reaksi reduksi ion logam menjadi logam :

$$
\begin{aligned}
& \mathrm{Cu}^{2+}+2 \mathrm{e} \rightarrow \mathrm{Cu} \\
& 2 \mathrm{H}^{+}+2 \mathrm{e} \rightarrow \mathrm{H}_{2}
\end{aligned}
$$

Reaksi pada anoda tergantung daripada material yang dipakai sebagai anoda, dapat menggunakan tembaga atau logam lain yang tidak larut. Bila anoda terbuat dari tembaga maka reaksinya merupakan reaksi pelarutan atau kebalikan daripada reaksi diatas (oksidasi) yakni dapat dilihat seperti pada Gambar 3.

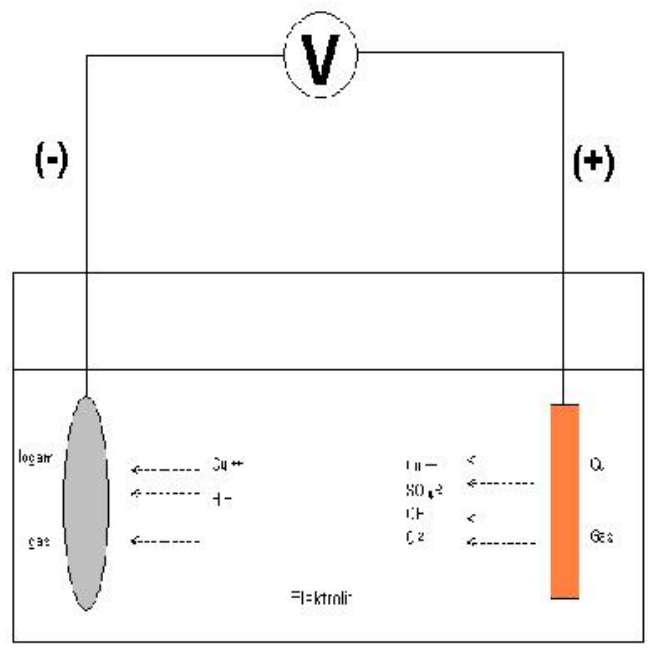

Gambar 3 : Ilustrasi proses pelapisan Tembaga

Jenis elektrolit yang dipakai di dalam proses pelapisan tembaga adalah tipe Alkali dan tipe Asam.

\section{a. Tipe Alkali}

\section{Alkali Sianida}

a. Larutan sianida tersusun dari campuran :

$$
\begin{array}{lll}
\mathrm{CuCN} & : 22,5-26,5 \mathrm{~g} / \mathrm{l} \\
\mathrm{NaCN} & : 30-50 \mathrm{~g} / \mathrm{l} \\
\mathrm{Na} 2 \mathrm{CO} 3 & : 15,0-60 \mathrm{~g} / \mathrm{l} \\
\mathrm{NaOH} & : \text { sampai } \mathrm{pH} \mathrm{12,}, 0-12,6
\end{array}
$$

b. Sianid Rochelle tersusun dari :

$\begin{array}{lll}\mathrm{CuCN} & : 16-30 \mathrm{~g} / \mathrm{l} \\ \mathrm{NaCN} & : 34,5-5 \mathrm{~g} / \mathrm{l} & \\ \mathrm{Na} 2 \mathrm{CO} 3 & : 15-60 \mathrm{~g} / \mathrm{l} & \\ \mathrm{NaOH} & : \text { sampai } \mathrm{pH} 12, & 0-12,6 \\ \text { Garam Rochelle }: 30-60 \mathrm{~g} / \mathrm{l} & \end{array}$

c. Larutan pekat yang tersusun dari :

$$
\begin{array}{ll}
\mathrm{CuCN} & : 67,5-120 \mathrm{~g} / \mathrm{l} \\
\mathrm{NaCN} & : 135-150 \mathrm{~g} / \mathrm{l} \\
\mathrm{Na} 2 \mathrm{CO} 3 & : 0-90 \mathrm{~g} / \mathrm{l} \\
\mathrm{NaOH} & : \text { sampai } \mathrm{pH} 12,0-12,6 \\
\text { Garam Rochelle }: 22,5-37,5 \mathrm{~g} / \mathrm{l}
\end{array}
$$

Alkali piroposfat yang tersusun dari :

$\begin{array}{ll}\text { Cu } & : 22,5-30 \mathrm{~g} / \mathrm{l} \\ \text { Piroposfat } & : 172,5-210,0 \mathrm{~g} / \mathrm{l} \\ \text { Amonia } & : 0,525-2,025\end{array}$




\section{b. Tipe Asam}

Sulfat:

$\mathrm{CuSO}_{4}, 5 \mathrm{H}_{2} \mathrm{O}: 195,0-247,5 \mathrm{~g} / \mathrm{l}$

$\mathrm{H}_{2} \mathrm{SO}_{4} \quad: 30,0-75,0 \mathrm{~g} / \mathrm{l}$

\section{Fluoborat:}

a. Cu rendah

$$
\begin{array}{ll}
\mathrm{Cu}\left(\mathrm{BF}_{42}\right) & : 225-337,5 \mathrm{~g} / \mathrm{l} \\
\mathrm{HBF}_{4} & : \operatorname{cukup}(\mathrm{pH}: 0,3-1,7)
\end{array}
$$

b. Cu tinggi :

$$
\mathrm{Cu}\left(\mathrm{BF}_{42}\right) \quad: 337,5450 \mathrm{~g} / \mathrm{l}
$$$$
\mathrm{HBF}_{4} \text { : cukup : }(\mathrm{pH}: 0,6)
$$

Kondisi operasi dari tiap proses di atas sangat berbeda-beda, misalnya pada larutan tembaga sianida pada $\mathrm{pH}-12$ :

$\begin{array}{ll}\text { Temperatur } & : \text { suhu kamar } \\ \text { Rapat arus } & :+4 \text { Amp/dm2 } \\ \text { Waktu } & : 1-4 \text { menit } \\ \text { Anoda } & : \text { tembaga } \\ \text { Perbandingan } & : 2 \text { dibanding } 3\end{array}$

Kegunaan dari masing-masing larutan di atas cukup luas antara lain elektrolit alkalis digunakan untuk pelapisan pada besi, sedangkan elektrolit asam untuk pelapisan benda-benda, dengan ukuran ketebalan yang tepat. Bak untuk pelapisan dengan proses alkali cukup dibuat dari baja tahan karat sedang untuk proses asam terbuat dari plat baja yang dilapis plastik, fiber glass reinforced polyster dan sebagainya.

\subsubsection{Proses Pelapisan Nikel dan Khrom}

Tujuan proses pelapisan ini adalah untuk memperoleh lapisan pelindung pada pemukaan logam yang tahan terhadap lingkungan. Selain itu lapisan ini meningkatkan tampak rupa, menambah kekerasan dan sebagainya. Pada umumnya lapisan nikel merupakan lapisan dasar yang kemudian harus dilapisi lebih tinggi daripada lapisan nikel.

Bagan alir dari proses secara keseluruhan dapat dilihat pada Gambar 4. Langkah-langkah proses seperti pada gambar tersebut mencakup tahapan-tahapan pembersihan, pembilasan air, pemolesan, pembersihan lemak (organik) pembilasan air, pelapisan khrom, pembilasan air dan pengeringan.

Seperti pada umumnya proses pelapisan listrik tahapan tersebut dapat berubah tergantung dari keadaan dan tingkat kebersihan dari benda yang akan diproses. Tahapan tersebut dapat dimulai sejak dari proses pemotongan atau proses-proses pembentukan lainnya, tetapi kadang-kadang juga langsung dengan degreasing kemudian dibilas sebelum proses pelapisan Nikel bilamana keadaan benda tersebut memungkinkan demikian. Bilamana lapisan dasarnya adalah lapisan tembaga maka prosesnya bila langsung dilapisi nikel melalui pembilasan atau penetralan. Benda yang sudah berkarat sudah barang tentu dibersihkan lebih dahulu melalui proses pembersihan dengan asam.

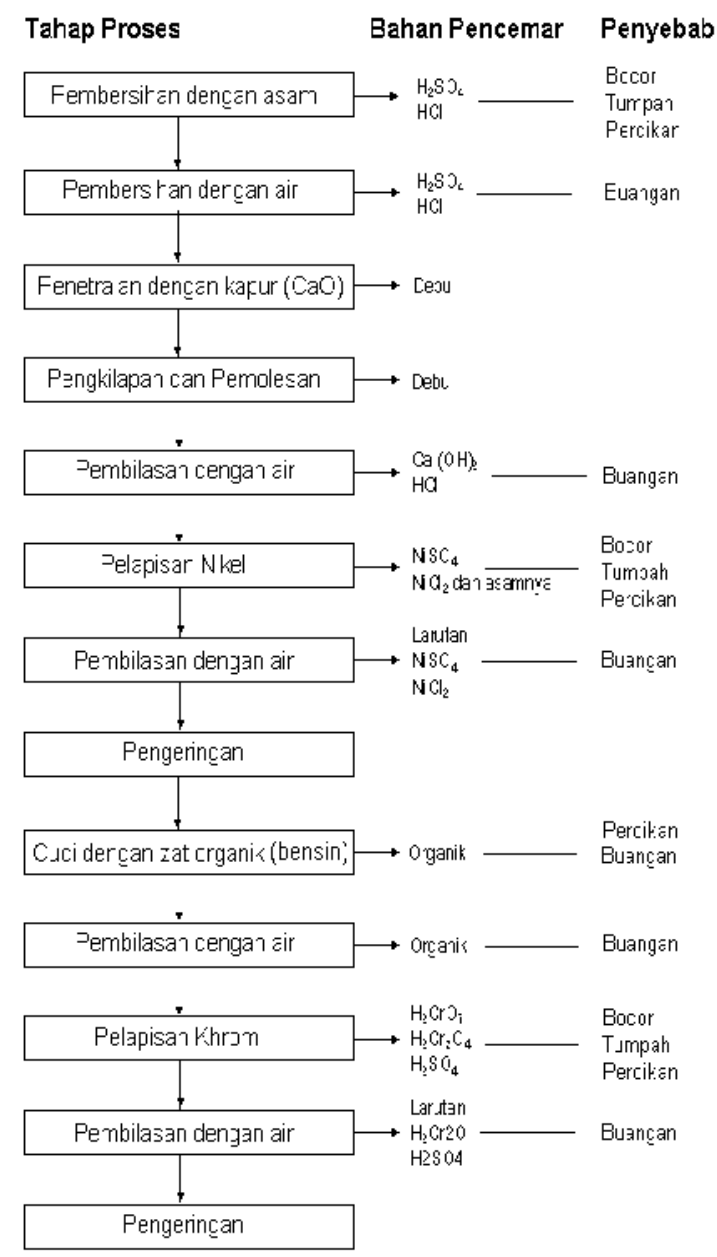

Gambar 4. Proses pelapisan Nikel dan Khrom dan unsur pencemar yang dikeluarkan.

Setelah proses pelapisan Nikel kadangkadang tidak memerlukan proses pemolesan sebelum memasuki proses pelapisan khrom. Dari tahapan proses tersebut beberapa diantaranya yaitu pembersihan lemak (degreasing), pembersihan dengan asam (pickling), prosesproses pembilasan dan pemolesan sudah diuraikan pada uraian mengenai proses pelapisan tembaga dihalaman depan.

\section{a. Pelapisan Nikel}

Proses pelapisan Nikel dapat dilaksanakan dalam berbagai jenis elektrolit. Jenis elektrolit yang dikenal adalah sebagai berikut :

1. Watts, terdiri dari sebagai berikut : 


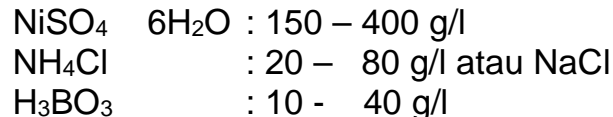

2. Khlorida Tinggi, terdiri :

$\begin{array}{cc}\mathrm{NiSO}_{4} & 6 \mathrm{H}_{2} \mathrm{O}: 150-300 \mathrm{~g} / \mathrm{l} \\ \mathrm{NH}_{4} \mathrm{Cl} & : 0-200 \mathrm{~g} / \mathrm{l} \\ \mathrm{H}_{3} \mathrm{BO}_{3} & : 20-50 \mathrm{~g} / \mathrm{l}\end{array}$

3. Sulfamat, terdiri dari

$\mathrm{Ni}\left(\mathrm{NH}_{4} \mathrm{SO}_{3}\right)_{2} \quad: 263,5-450 \mathrm{~g} / \mathrm{l}$

$\mathrm{NiCl}_{2} .6 \mathrm{H}_{2} \mathrm{O}: 0-30 \mathrm{~g} / \mathrm{l}$

$\mathrm{H}_{3} \mathrm{BO}_{3} \quad: 30-45 \mathrm{~g} / \mathrm{l}$

4. Fluoborat, terdiri dari :
$\mathrm{Ni}\left(\mathrm{BF}_{4}\right)_{2}$
$: 225-300 \mathrm{~g} / \mathrm{l}$
$\mathrm{NiCl}_{2} .6 \mathrm{H}_{2}$
$: 0-15 \mathrm{~g} / \mathrm{l}$
$\mathrm{H}_{3} \mathrm{BO}_{3}$
$: 15-30 \mathrm{~g} / \mathrm{l}$

5. Barrel, terdiri dari :

$\begin{array}{lll}\mathrm{NiSO}_{4} 6 \mathrm{H}_{2} \mathrm{O} & : 160-250 \mathrm{~g} / \mathrm{l} \\ \mathrm{NH}_{4} \mathrm{Cl} & : 0-30 \mathrm{~g} / \mathrm{l} \\ \mathrm{NiCl}_{2} \cdot 6 \mathrm{H}_{2} \mathrm{O} & : 0 & -30 \mathrm{~g} / \mathrm{l} \\ \mathrm{MgSO}_{4} \cdot 7 \mathrm{H}_{2} \mathrm{O} & : 0 & -120 \mathrm{~g} / \mathrm{l} \\ \mathrm{Na}_{2} \mathrm{SO}_{4} & : 0 & -50 \mathrm{~g} / \mathrm{l}\end{array}$

Kondisi operasi dari masing-masing proses yang menggunakan elektrolit tersebut diatas berbeda-beda, misalnya untuk pelapisan nikel dengan elektrolit Watts dilakukan pada :

$\mathrm{pH}$

Suhu

Rapat arus

Waktu

Anoda

Perbandingan luas permukaan

Katoda: Anoda

:1 dibanding 2

Yang penting digunakan dari prosesproses di atas adalah dengan proses Watts karena dengan adanya pertimbanganpertimbangan bahwa elektrolitnya dibuat dari bahan-bahan yang mudah didapat, ekonomis dan aman. Di dalam proses pelapisan Nikel bak yang digunakan adalah plat baja yang dilapisi fiber glass reinforced plastik, plastik karet atau lainnya.

\section{b. Pelapis Khrom}

Pelapis khrom dapat dilaksanakan dalam elektrolit yang mengandung :

- Asam khromat

- Asam Sulfat

- Potasium chlorida

Selain ini ada beberapa jenis elektrolit lain untuk tujuan dekoratif dan ada juga untuk tujuan pelapisan keras (pelapisan khrom keras).

\section{PENCEMARAN AIR OLEH INDUSTRI PELAPISAN LOGAM}

\subsection{Sumber Pencemaran Air oleh Industri Pelapisan Logam}

Seperti telah diuraikan di atas, beberapa jenis proses pelapisan logam, khususnya untuk pelapisan tembaga, nikel dan khrom menggunakan bahan-bahan kimia yang berbedabeda yang umumnya bersifat racun yang dapat mencemari lingkungan. Tiap tahapan proses dapat menghasilkan limbah yang berbeda-beda.

\section{Tahap Pertama}

Pembersihan permukaan barang logam dari kotoran-kotoran yang berupa karat, debu serta lemak. Pada pembersihan awal ini umumnya digunakan asam khlorida, asam sulfat, atau sabun pencuci serta air pembilas yang cukup banyak. Dari tahapan ini terlihat adanya bahan buangan sisa asam dan zat organik lain.

\section{Tahap Kedua}

Pembersihan secara mekanis biasanya dilakukan dengan cara ampelas, dan polis yang menggunakan alat dan bahan abrasif. Dari tahap ini akan dihasilkan banyak sekali debu-debu logam, bahan abrasif yang dapat mengganggu lingkungan pabrik.

\section{Tahap Ketiga}

Pencucian dan penetralan dengan air kapur. Dari tahap ini akan keluar bahan-bahan buangan yang bersifat basis.

\section{Tahap Keempat}

Pelapisan listrik yang akan menggunakan bahan-bahan kimia sebagai elektrolit antara lain senyawa-senyawa sulfat, khlorida, khromat, sianida, fosfat dan lain-lain. Pengotoran sekeliling adalah akibat dari kebocoran percikan, tumpah, tetesan-tetesan pada waktu pengangkatan benda-benda, uap elektrolit, maupun gas-gas hasil reaksi elektrolisa. Jumlah bahan pengotor dari tahap proses ini sangat tergantung pada sistem kerja dan peralatan yang digunakan.

\subsection{Jenis-jenis bahan pencemar}

Bahan-bahan buangan (seperti terlihat pada Tabel 1) yang mencemari lingkungan dapat berupa :

\section{Pertama}

Bahan buangan yang berupa cairan yang mengandung antara lain : Sianida, ion tembaga, ion nikel, khromat dan bi khromat, asam borat, nitrat, asam fosfat, zat-zat organik seperti minyak, lemak, bensin dan lain-lain. 


\section{Kedua}

Bahan-bahan buangan yang berupa gas dan uap yang akan mencemari udara sekeliling antara lain : Uap sianida, khromat, gas-gas hasil proses elektrolisa antara lain $\mathrm{H} 2$ dan pelarut organik misalnya trikhloretilen, bensin dan bahan pengecer (thinner)

\section{Ketiga}

Bahan-bahan buangan yang serupa bahan padat antara lain: debu-debu logam, debu-debu abrasif, endapan-endapan garam yang timbul sebagai hasil reaksi kimia pada proses pengolahan air buangan. Bahan-bahan buangan yang berupa debu-debu halus dari pekerjaan ampelas dan polis akan dapat mengotori udara tempat kerja dan udara sekeliling.

\subsection{Sifat Bahan Pencemar dan Bahayanya.}

Beberapa hal yang penting untuk diketahui dari bahan-bahan pencemaran tersebut adalah sifat serta bahayanya terutama bahaya terhadap manusia maupun kehidupan lain sekelilingnya. Sifat bahan pencemar yang keluar dari industri pelapisan listrik dapat dilihat pada Tabel 1.

Tabel 1 : Jenis dan sifat behan pencemar di dalam proses pelapisan logam.

\begin{tabular}{|c|c|c|}
\hline $\begin{array}{c}\text { Jenis } \\
\text { Bahan } \\
\text { Pencemar }\end{array}$ & Bentuk & Sifat dan Bahayanya \\
\hline Sianida & $\begin{array}{l}\text { Kristal } \\
\text { Cairan } \\
\text { Gas }\end{array}$ & $\begin{array}{l}\text { HCN masuk dalam tubuh manusia } \\
\text { melalui lambung paru-paru, kulit } \\
\text { yang basah oleh keringat. } \\
\text { Ketiga jenis ini sangat beracun dan } \\
\text { mematikan }\end{array}$ \\
\hline Tembaga & $\begin{array}{l}\text { Kristal } \\
\text { Cairan }\end{array}$ & $\begin{array}{l}\text { Iritasi terhadap kulit, korosif } \\
\text { beberapa ppm dalam air } \\
\text { membunuh lumut, sampai berpuluh } \\
\text { gram tertelan dapat mematikan } \\
\text { manusia. }\end{array}$ \\
\hline Nikel & $\begin{array}{l}\text { Kristal garam } \\
\text { Cairan } \\
\text { Padatan } \\
\text { Logam }\end{array}$ & $\begin{array}{l}\text { Tidak beracun dalam keadaan } \\
\text { logam tetapi dalam keadaan cairan } \\
\text { sebagai penyebab kanker, korosif, } \\
\text { iritan "nickel eczema". }\end{array}$ \\
\hline $\begin{array}{l}\text { Khromat } \\
\text { dan } \\
\text { bikhromat }\end{array}$ & $\begin{array}{l}\text { Kristal } \\
\text { Kuning dan } \\
\text { merah } \\
\text { Cairan }\end{array}$ & $\begin{array}{l}\text { Asam bikhromat adalah keras } \\
\text { dapat membakar bahan organik } \\
\text { dengan mudah, iritan sekali dapat } \\
\text { menyebabkan "chrome noles" pada } \\
\text { kulit. } \\
\text { Masuk tubuh lewat mulut dan } \\
\text { hidung, sangat beracun dan } \\
\text { penyebab kanker paru-paru }\end{array}$ \\
\hline $\begin{array}{l}\text { Asam } \\
\text { borat }\end{array}$ & $\begin{array}{l}\text { Kristal } \\
\text { Cairan }\end{array}$ & $\begin{array}{l}\text { Bukan racun, tetapi jika tertelan } \\
\text { sampai beberapa puluh gram } \\
\text { berupa racun keras. } \\
\text { Dalam keadaaan cairan dengan } \\
\text { konsentrasi }+5 \% \text { menyebabkan } \\
\text { iritasi dan dapat merusak kulit }\end{array}$ \\
\hline $\begin{array}{l}\text { Asam } \\
\text { Nitrat }\end{array}$ & Cairan & $\begin{array}{l}\text { Oksidator-korosif-iritan. } \\
\text { Asap coklatnya sangat iritan } \\
\text { terhadap mata, kulit dan } \\
\text { pernapasan. }\end{array}$ \\
\hline
\end{tabular}

\begin{tabular}{|c|c|c|}
\hline $\begin{array}{l}\text { Asan } \\
\text { Posfat }\end{array}$ & Cairan & $\begin{array}{l}\text { Korosif, iritan, kalau kena panas } \\
\text { dapat mengeluarkan asap posfory } \\
\text { yang beracun }\end{array}$ \\
\hline $\begin{array}{c}\text { Minyak } \\
\text { dan lemak }\end{array}$ & $\begin{array}{l}\text { Cairan } \\
\text { Padatan }\end{array}$ & $\begin{array}{l}\text { Dari rasa dan baunya dalam air } \\
\text { ikan dapat mati lemas, dan } \\
\text { ganggang palkton akan mati } \\
\text { Mengganggu realisasi dan } \\
\text { fotosintetis }\end{array}$ \\
\hline Bensin & Cairan & $\begin{array}{l}\text { Mudah sekali menguap dan } \\
\text { terbakar }\end{array}$ \\
\hline Hidrogen & Gas & $\begin{array}{l}\text { Mudah sekali menguap dan } \\
\text { terbakar }\end{array}$ \\
\hline $\begin{array}{c}\text { Trikloretile } \\
n\end{array}$ & Gas & $\begin{array}{l}\text { Pada manusia menyebabkan } \\
\text { dermatites. } \\
\text { Menghirup terus menerus } \\
\text { mengakibatkan sakit kepala } \\
\text { bahkan merusak lever. } \\
\text { Mudah menguap dan kalau kena } \\
\text { api menimbulkan gas beracun } \\
\text { sekali (fosgen }\end{array}$ \\
\hline $\begin{array}{l}\text { Debu- } \\
\text { debu } \\
\text { logam }\end{array}$ & $\begin{array}{l}\text { Padatan } \\
\text { yang halus } \\
\text { sekali }\end{array}$ & $\begin{array}{l}\text { Iritasi, kalau dihirup dapat sesak } \\
\text { napas dan dapat mengakibatkan } \\
\text { pneumoconiosis. } \\
\text { Mengotori ruangan }\end{array}$ \\
\hline $\begin{array}{l}\text { Debu- } \\
\text { debu } \\
\text { abrasif }\end{array}$ & $\begin{array}{l}\text { Padatan } \\
\text { yang halus } \\
\text { sekali }\end{array}$ & $\begin{array}{l}\text { Iritasi, sesak napas sampai } \\
\text { pneumoconiosis mungkin silicosis. } \\
\text { Mengotori ruangan }\end{array}$ \\
\hline $\begin{array}{l}\text { Zat } \\
\text { pengencer } \\
\text { atau } \\
\text { thinner }\end{array}$ & $\begin{array}{l}\text { Cairan } \\
\text { dengan } \\
\text { berbagai } \\
\text { komposisi }\end{array}$ & $\begin{array}{l}\text { Bau dan mudah menguap dan } \\
\text { terbakar } \\
\text { Dermatitis, iritasi teggorokan } \\
\text { sampai bronchitis. }\end{array}$ \\
\hline
\end{tabular}

\section{TINJAUAN PROSES PENGOLAHAN AIR LIMBAH INDUSTRI PELAPISAN LOGAM}

\subsection{Prinsip Dasar Pengolahan Beberapa Bahan Kimia}

Air limbah yang keluar dari industri pelapisan logam dan khusus industri pelapisan nikel, khrom, dan tembaga mengandung zat-zat kimia berbahaya misalnya senyawa-senyawa khrom, nikel, tembaga, sulfat, khlorida, sianida, serta zat-zat organik seperti lemak, minyak, dan lain-lain.

Prinsip dasar pengolahan beberapa bahan kimia berbahaya tersebut adalah mengubah bahan tersebut agar menjadi produk-produk lain yang tidak berbahaya sehingga tidak mencemari lingkungan.

\subsubsection{Pengolahan Senyawa Khrom Valensi Enam $\left(\mathrm{Cr}^{6+}\right)$}

Pengolahan khrom ini dapat dilakukan dengan tiga cara antara lain :

\section{a. Cara reduksi $\mathrm{Cr}^{6+}$ menjadi $\mathrm{Cr}^{3+}$ kemudian disusul dengan pengendapan $\mathrm{Cr}^{3+}$ sebagai hidroksida.}

Seperti halnya proses-proses kimia lain, maka proses reduksi $\mathrm{Cr}^{6+}$ menjadi $\mathrm{Cr}^{3+}$ dipengaruhi oleh beberapa faktor-faktor 
diantaranya adalah : waktu reaksi, $\mathrm{pH}$, larutan konsentrasi $\mathrm{Cr}^{6+}$ dan banyaknya serta jenisnya bahan pereduksi yang dipakai. Hubungan waktu reduksi dengan $\mathrm{pH}$, dan konsentrasi $\mathrm{Cr}^{6+}$. Dari diagram diatas jelas bahwa makin tinggi konsentrasi $\mathrm{Cr}^{6+}$ dalam larutan proses reduksinya lebih lama daripada dengan konsentrasi rendah.

\section{Reduksi dengan ferrosulfat :}

$\mathrm{CrO}_{3}+\mathrm{H}_{2} \mathrm{O} \rightarrow \mathrm{H}_{2} \mathrm{CrO}_{4}$

$2 \mathrm{H}_{2} \mathrm{CrO}_{4}+6 \mathrm{FeSO}_{4}+6 \mathrm{H}_{2} \mathrm{So}_{4} \rightarrow \mathrm{Cr}_{2}(\mathrm{SO})_{43}+3 \mathrm{Fe}$ $(\mathrm{SO})_{4}$

Reduksi dengan $\mathrm{SO}_{3}$ :

$2 \mathrm{H}_{2} \mathrm{CrO}_{4}+2 \mathrm{H}_{2} \mathrm{SO}_{3} \rightarrow \mathrm{Cr}_{2}(\mathrm{SO})_{4}+3 \mathrm{H}_{2} \mathrm{O}$

Reduksi dengan bisulfat :

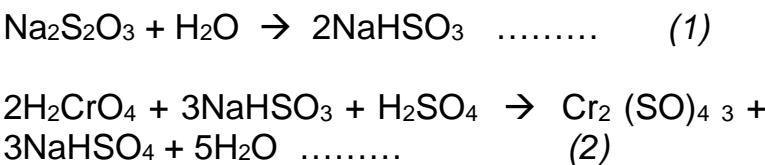

b. Cara kedua adalah dengan mengikat $\mathrm{Cr}^{6+}$ dengan resin tertentu (ion exchanger) dengan mengatur pH antara 4,5-5,0.

\section{c. Cara ketiga adalah pengambilan kembali $\mathrm{Cr}^{6+}$ dan $\mathrm{Cr}^{3+}$ dengan cara pengentalan.}

Di antara ketiga cara pengolahan khrom tersebut yang banyak dilakukan di Indonesia adalah yang cara pertama yaitu proses reduksi. Dalam praktek cara reduksi ini lebih lanjut dapat diuraikan sebagai berikut :

- Pertama-tama pH larutan diturunkan terlebih dahulu sampai mendekati 3 dengan penambahan sulfat.

- Kemudian ditambahkan bahan kimia misalnya metabisulfat/hidrosulfat/ ferrosulfat, sebagai bahan produksi yang mereduksi $\mathrm{Cr}^{6+}$ menjadi $\mathrm{Cr}^{3+}$

- Larutan $\mathrm{Cr}^{3+}$ tersebut diberi kapur untuk mengendapkan $\mathrm{Cr}^{3+}$ dalam bentuk $\mathrm{Cr}(\mathrm{OH})_{3}$

Reaksi pada proses pengendapan dengan kapur adalah sebagai berikut :

$$
\begin{aligned}
& \mathrm{Cr}_{2}(\mathrm{SO})_{4}+3 \mathrm{Ca}(\mathrm{OH})_{2} \rightarrow 2 \mathrm{Cr}(\mathrm{OH})_{3}+\mathrm{CaSO}_{4} \\
& \mathrm{Fe}(\mathrm{SO})_{4}+3 \mathrm{Ca}(\mathrm{OH})_{2} \rightarrow 2 \mathrm{Fe}(\mathrm{OH})_{3}+\mathrm{CaSO}_{4}
\end{aligned}
$$

\subsubsection{Pengolahan Senyawa Khrom Valensi $3\left(\mathrm{Cr}^{3+}\right)$}

Cara pemisahan khrom valensi tiga $\left(\mathrm{Cr}^{3+}\right)$ dilakukan antara lain :

- Proses pengendapan dengan kapur seperti telah diuraikan pada pengolahan metabisulfat/hidrosulfat/ferrosulfat, sebagai bahan produksi yang mereduksi $\mathrm{Cr}^{6}$, atau dengan menggunakan soda kostik.

- Cara kedua adalah mengkonsentrasikan larutan kemudian diikat dengan resin dalam proses ion exchange.

Di dalam cara pengendapan dengan kapur atau soda kostik $\mathrm{pH}$ paling efektif adalah antara 3,59,5. Endapan (lumpur) $\mathrm{Cr}(\mathrm{OH})_{3}$ dan $\mathrm{Fe}(\mathrm{OH})_{3}$ ' biasanya masih mengandung 95\% air. Endapan ini dapat dipisahkan dengan pengeringan (filter beds) atau penyaringan (filter aid).

\subsubsection{Pengolahan senyawa tembaga}

Senyawa tembaga dapat diolah dengan baberapa cara antara lain :

- Pertama dengan cara mengendapkan sebagai hidroksida atau sulfida.

- Kedua menangkap ion $\mathrm{Cu}$ dengan resin tertentu dalam proses penukar ion atau ion exchange, dengan proses ini kadar $\mathrm{Cu}$ dari 1 ppm dapat diturunkan sampai 0,03 ppm.

- Ketiga dengan cara penguapan dan elektrolisa, cara ini lebih sesuai untuk air buangan dengan kadar $\mathrm{Cu}$ rendah.

Cara yang banyak dipakai dalam pengolahan $\mathrm{Cu}$ adalah proses pengendapan dengan kapur. Dengan menambahkan kapur dan mengatur $\mathrm{pH}$ antara 9,3 - 10,3 hidroksida tembaga beserta logam-logam berat lainnya dapat mengendap sempurna.

Pada $\mathrm{pH}$ tersebut kelarutan tembaga hidroksida adalah yang terendah yaitu $0,01 \mathrm{mg} / \mathrm{l}$. Pengendapan dengan kapur ini akan terganggu bila dalam larutan mengandung sianida, pirosulfat atau senyawa kompleks lainnya. Untuk keadaan seperti ini sianida harus dipisahkan terlebih dahulu. Khusus untuk larutan yang mengandung pirosulfat, pengendapan dilakukan pada $\mathrm{pH}$ tinggi yaitu sekitar 12 .

\subsubsection{Pengolahan Senyawa Nikel}

Pengolahan senyawa nikel umumnya dilakukan dengan cara-cara sebagai berikut :

- Mengendapkan dengan kapur yang dilakukan pada $\mathrm{pH}$ sekitar 12. Pengendapan senyawa nikel dapat pula dilakukan dengan ferrosulfat, juga pada $\mathrm{pH}$ sekitar 10 .

- Cara kedua adalah proses pemindahan kation atau exchanger, cara ini mampu menghasilkan air buangan bebas nikel. 
Kesulitan akan timbul bila di dalam larutan terdapat sianida, sebab sianida akan merusak resin yang digunakan.

- Cara ketiga adalah dengan penguapan dan osmosa balik (reverse osmosis). Pengolahan bahan buangan nikel biasanya dilakukan bersama-sama dengan unsur-unsur berbahaya lainnya. Diantaranya ketiga cara yang telah diuraikan diatas paling banyak dilakukan adalah pengendapan dengan kapur.

\subsubsection{Pengolahan Senyawa Sianida}

Prinsip pengolahan sianida dari air buangan adalah merusak/mengoksider sianida dengan khlor aktif. Sianida teroksida menjadi sianida $\mathrm{CNO}$ dan akhirnya menjadi $\mathrm{CO}_{2}$ dan $\mathrm{N}_{2}$.

Proses-proses lainnya adalah perusakan sianida secara elektrolisa, dan dapat pula dilakukan pengolahan secara penguapan.

Pengolahan dengan khlor aktif dilakukan dengan menaikkan $\mathrm{pH}$ larutan terlebih dahulu antara lain dengan penambhana $\mathrm{NaOH}$, kemudian diberi khlor aktif/kaporit atau natrium hipokhlorit. Reaksi yang terjadi adalah sebagai berikut :

$\mathrm{CN}-+\mathrm{HOCl} \rightarrow \mathrm{CNCl}-+\mathrm{OH}^{-} \quad \ldots \ldots \ldots$

$\mathrm{CNCl}+2 \mathrm{OH} \rightarrow \mathrm{CNO}-+\mathrm{Cl}+\mathrm{H}_{2} \mathrm{O} \ldots \ldots$.

$2 \mathrm{CNO}+3 \mathrm{OCl}+\mathrm{H}_{2} \mathrm{O} \rightarrow \mathrm{CO}_{2}+3 \mathrm{Cl}+2 \mathrm{HO} \ldots$

Reaksi (1) berjalan cepat sekali, sedang reaksi (2) lambat $\mathrm{pH}$ sekitar 9,0 kecuali kalau ada kelebihan khlor. Apabila $\mathrm{pH}$ diatur sekitar 10 , waktu oksidasi sianida sampai menjadi CNO selesai hanya sekitar 5 menit. Bila dalam larutan ada kation $\mathrm{Na}^{+}$, reaksi akan berjalan lambat sekitar 30 sampai 2 jam.

\subsubsection{Pengolahan Lemak dan Minyak}

Pengolahan lemak, minyak atau bahan organik lain biasanya dilakukan dalam dua tahap yakni tahap pertama (Pengolahan Primer) adalah memisahkan minyak dari air dengan adanya perbedaan berat jenis. Secara praktis air buangan ditampung dalam bak yang cukup besar, dan didiamkan beberapa waktu sampai terjadi pemisahan minyak/lemak sempurna.

Minyak dan lemak akan mengapung dan dapat dipisahkan dengan cara skimming. Pemisahan dengan cara gravitasi ini sangat dipengaruhi oleh desain bak penampung, dan oleh waktu pemisahan. Makin lama waktu pemisahan makin sempurna hasilnya.

Cara yang ke dua menghancurkan atau merusak emulsi minyak dengan cara kimia, listrik atau fisis.
Diantara ke dua metode ini cara kimia paling banyak dilakukan. Secara garis besar ada 4 cara sebagai berikut : penambahan koagulan, penambahan asam, penambahan garam dan pemanasan dan penambahan dan pemecah emulsi (demulgators)

Di dalam prakteknya, koagulan yang banyak dipakai adalah garam-garam aluminium atau besi yang akan menghasilkan lumpur hidroksida, aluminium atau besi yang mengandung banyak air.

Dapat pula dilakukan dengan asam, biasanya $\mathrm{HCl}$ atau $\mathrm{H}_{2} \mathrm{SO} 4$, akan menghasilkan air buangan yang asam yang perlu dinetralisir dahulu. Proses flotasi ini prinsipnya adalah proses penempelan minyak pada permukaan gelembung-gelembung udara yang sengaja diteimbulkan dengan pengadukan dan tiupan udara dalam larutan.

Pemisahan dengan flotasi ini cukup effektif, tetapi diperlukan peralatan khusus dan bahan kimia khusus pula misalnya frother dan aktivator.

\subsection{Pengolahan Air limbah Pelapisan logam Terpadu}

Yang dimaksud dengan pengolahan terpadu disini adalah pengolahan dari semua jenis air buangan dalam satu sistem pengolahan.

Pada dasarnya air-air buangan dapat dikategorikan dalam tiga jenis :

- Air Buangan yang mengandung asam, antara lain $\mathrm{H}_{2} \mathrm{SO}_{4}, \mathrm{HCl}, \mathrm{H}_{2} \mathrm{CrO}_{4}, \mathrm{H}_{2} \mathrm{Cr}_{2} \mathrm{O}_{7}$, $\mathrm{NiSO}_{4}, \mathrm{CuP}_{2} \mathrm{O}_{7}, \mathrm{NiCl}_{2}$, dengan kepekatan berbeda-beda.

- Air buangan yang mengandung, $\mathrm{NaCN}$, $\mathrm{CuCN}, \mathrm{Ca}(\mathrm{OH})_{2}, \mathrm{NaOH}$, dan lain-lain dengan konsentrasi yang berbeda-beda.

- Air buangan yang mengandung senyawasenyawa organik (lemak, sabun, minyak dan lain-lain).

Jenis-jenis air buangan tersebut harus dipisahkan sejak awal antara lain dengan menampung dalam bak terlebih dahulu atau dapat pula langsung ke tempat pengolahan. $\mathrm{Di}$ sini perlu diperhatikan bahwa air buangan alkalis sama sekali tidak boleh dicampur dengan air buangan yang asam.

Air buangan yang mengandung sianida sama sekali tidak boleh ditampung dahulu dalam satu bak, sedang air buangan yang mengandung khrom ditampung dalam bak yang berbeda.

Besarnya bak dibuat dengan ukuran yang dapat menampung air buangan sekurangkurangnya selama 10 jam, dengan maksud agar dapat diperoleh air buangan yang homogen untuk memudahkan pengolahan selanjutnya.

Untuk suatu unit pengolahan yang berkapasitas $20 \mathrm{~m}^{3} / \mathrm{jam}$ (6 ton/jam buangan 
sianida 8 ton/jam buangan khrom dan 6 ton/jam buangan lainnya) diperlukan bak penampung air sianida $5 \times 6 \times 3=90 \mathrm{~m}^{3}$ sebanyak dua buah, yang dipakai bergantian, sedang untuk air buangan yang mengandung khrom dibuat dua bak ukuran $6,7,3 \mathrm{~m}^{3}$.

Air buangan sianida dari bak penampung dialirkan ke bak pengaduk oksidasi dimana kedalam bak pengaduk ini ditambahkan $\mathrm{NaOCl}$ dan kemudian air kapur. Dalam bak pengaduk ini akan terjadi reaksi oksidasi dimana sianida akan terurai menjadi $\mathrm{CO}^{2}$ dan $\mathrm{N}^{2}$ pada $\mathrm{pH}$ sekitar 10 . Dalam reaksi oksidasi ini untuk tiap bagian sianida diperlukan 8 bagian khlor, reaksi berjalan cukup cepat dan berlangsung sekitar 30 menit, endapan yang terjadi dipisahkan dalam bak pengendap.

Air buangan yang mengandung khrom dialirkan ke bak pengaduk, kedalam bak ini ditambahkan larutan sulfit dan asam sulfat untuk mengatur $\mathrm{pH}$ antara 2-3. Proses reduksi akan terjadi $\mathrm{Cr}^{6+}$, larutan $\mathrm{Cr}^{3+}$ dialirkan ke bak pengendap. Dalam bak pengendapan senyawa $\mathrm{Cr}_{3}+$ akan bereaksi dengan senyawa basa $\mathrm{Ca}$ $(\mathrm{OH})_{2}$ dan pengendap sebagai $\mathrm{Cr}(\mathrm{OH})_{3}$.

Pada proses ini $\mathrm{pH}$ diatur sekitar 8-9, bila perlu dengan tambahan air kapur. Disamping khrom, juga logam-logam lain turut mengandap sehingga air yang melimpah keluar dari bak bebas dari khrom, nikel, tembaga maupun sianida.

Skema proses pengolahan air Limbah pelapisan logam secara terpadu dapat dilihat seperti pada Gambar 5.

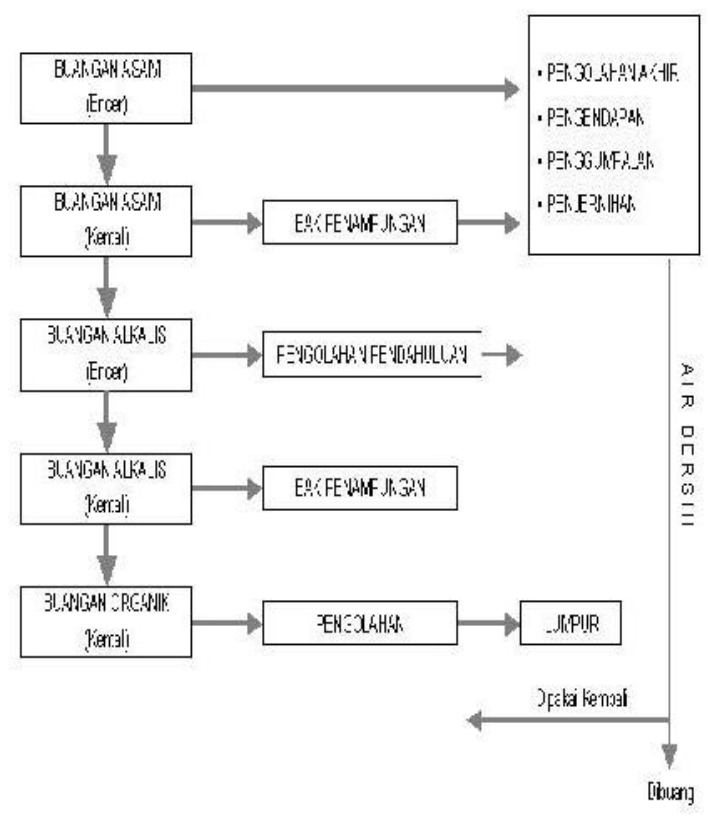

Gambar 5: Pengolahan air limbah pelapisan logam terpadu

\subsection{PILOT PLANT IPAL INDUSTRI KECIL PELAPISAN LOGAM}

Unit IPAL industri kecil pelapisan logam ini dirancang sedemikan rupa agar cara operasinya mudah dan biaya perasionalnya murah. Unit ini terdiri dari perangkat utama dan perangkat penunjang. Perangkat utama dalam sistem pengolahan terdiri dari unit pencampur statis (static mixer), bak antara, bak koagulasi-flokulasi, saringan multimedia/ kerikil, pasir, karbon, mangan zeolit (multimedia filter), saringan karbon aktif (activated carbon filter), dan saringan penukar ion (ion exhange filter).

Perangkat penunjang dalam sistem pengolahan ini dipasang untuk mendukung operasi treatment yang terdiri dari pompa air baku untuk intake (raw water pump), pompa dosing (dosing pump), tangki bahan kimia (chemical tank), pompa filter untuk mempompa air dari bak koagulasi-flokulasi ke saringan/filter, dan perpipaan serta kelengkapan lainnya.

Proses pengolahan diawali dengan memompa air baku dari bak penampungan kemudian diinjeksi dengan bahan kimia ferrosulfat dan PAC (Poly Allumunium Chloride), kemudian dicampur melalui static mixer supaya bercampur dengan baik. Kemudian air baku yang teroksidasi dialirkan ke bak koagulasi-flokulasi dengan waktu tinggal sekitar 2 jam. Setelah itu air dari bak dipompa ke saringan multimedia, saringan karbon aktif dan saringan penukar ion. Hasil air olahan di masukkan ke bak penampungan untuk digunakan kembali sebagai air pencucian. Diagram proses IPAL industri pelapisan logam dapat dilihat seperti pada Gambar 6.

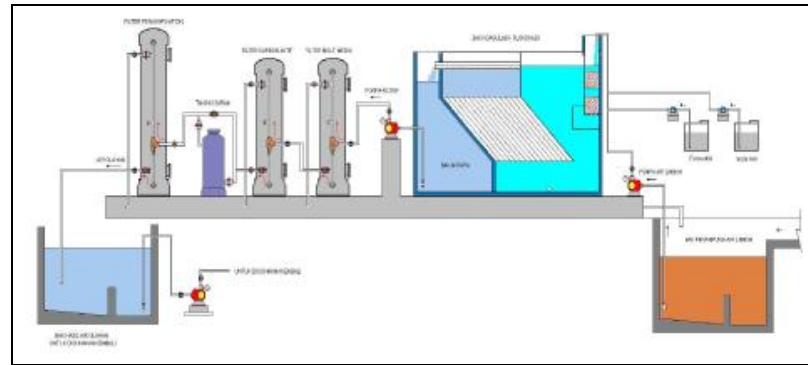

Gambar 6. Proses Pengolahan Limbah Industri Kecil Pelapisan Logam

\subsubsection{Cara kerja IPAL}

\section{a. Pompa Air Baku (Raw water pump)}

Pompa air baku yang digunakan jenis setrifugal dengan kapasitas maksimum yang dibutuhkan unutk unit pengolahan (daya tarik minimal 9 meter dan daya dorong 40 meter). Air baku yang dipompa berasal dari bak akhir dari 
proses pengendapan pada hasil buangan limbah industri pelapisan logam.

\section{b. Pompa Dosing (Dosing pump)}

Merupakan peralatan untuk mengijeksi bahan kimia (ferrosulfat dan PAC) dengan pengaturan laju alir dan konsentrasi tertentu untuk mengatur dosis bahan kimia tersebut. Tujuan dari pemberian bahan kimia ini adalah sebagai oksidator.

\section{c. Pencampur Statik (Static mixer)}

Dalam peralatan ini bahan-bahan kimia dicampur sampai homogen dengan kecepatan pengadukan tertentu untuk menghindari pecah flok.

\section{d. Bak Koagulasi-Flokulasi}

Dalam unit ini terjadi pemisahan padatan tersuspensi yang terkumpul dalam bentuk-bentuk flok dan mengendap, sedangkan air mengalir overflow menuju proses berikutnya.

\section{e. Pompa Filter}

Pompa yang digunakan mirip dengan pompa air baku. Pompa ini harus dapat melalui saringan multimedia, saringan karbon aktif, dan saringan penukar ion.

\section{f. Saringan Multimedia}

Air dari bak koagulasi-flokulasi dipompa masuk ke unit penyaringan multimedia dengan tekanan maksimum sekitar 4 Bar. Unit ini berfungsi menyaring partikel kasar yang berasal dari air olahan. Unit filter berbentuk silinder dan terbuat dari bahan fiberglas. Unit ini dilengkapi dengan keran multi purpose (multiport), sehingga untuk proses pencucian balik dapat dilakukan dengan sangat sederhana, yaitu dengan hanya memutar keran tersebut sesuai dengan petunjuknya. Tinggi filter ini mencapai $120 \mathrm{~cm}$ dan berdiameter $30 \mathrm{~cm}$. Media penyaring yang digunakan berupa pasir silika dan mangan zeolit. Unit filter ini juga didisain secara khusus, sehingga memudahkan dalam hal pengoperasiannya dan pemeliharaannya. . Dengan menggunakan unit ini, maka kadar besi dan mangan, serta beberapa logam-logam lain yang masih terlarut dalam air dapat dikurangi sampai sesuai dengan kandungan yang diperbolehkan untuk air minum.

\section{g. Saringan Karbon Aktif}

Unit ini khusus digunakan untuk penghilang bau, warna, logam berat dan pengotor-pengotor organik lainnya. Ukuran dan bentuk unit ini sama dengan unit penyaring lainnya. Media penyaring yang digunakan adalah karbon aktif granular atau butiran dengan ukuran $1-2,5 \mathrm{~mm}$ atau resin sintetis, serta menggunakan juga media pendukung berupa pasir silika pada bagian dasar.

\section{h. Saringan Penukar Ion}

Pada proses pertukaran ion, kalsium dan magnesium ditukar dengan sodium. Pertukaran ini berlangsung dengan cara melewatkan air sadah ke dalam unggun butiran yang terbuat dari bahan yang mempunyai kemampuan menukarkan ion. Bahan penukar ion pada awalnya menggunakan bahan yang berasal dari alam yaitu greensand yang biasa disebut zeolit, Agar lebih efektif Bahan greensand diproses terlebih dahulu. Disamping itu digunakan zeolit sintetis yang terbuat dari sulphonated coals dan condentation polymer. Pada saat ini bahanbahan tersebut sudah diganti dengan bahan yang lebih efektif yang disebut resin penukar ion. Resin penukar ion umumnya terbuat dari partikel cross-linked polystyrene. Apabila resin telah jenuh maka resin tersebut perlu diregenerasi. Proses regenerasi dilakukan dengan cara melewatkan larutan garam dapur pekat ke dalam unggun resin yang telah jenuh. Pada proses regenerasi terjadi reaksi sebaliknya yaitu kalsium dan magnesium dilepaskan dari resin, digantikan dengan sodium dari larutan garam.

\section{i. Sistem Jaringan Perpipaan}

Sistem jaringan perpipaan terdiri dari empat bagian, yaitu jaringan inlet (air masuk), jaringan outlet (air hasil olahan), jaringan bahan kimia dari pompa dosing dan jaringan pipa pembuangan air pencucian. Sistem jaringan ini dilengkapi dengan keran-keran sesuai dengan ukuran perpipaan. Diameter yang dipakai sebagian besar adalah 1" dan pembuangan dari bak koagulasi-flokulasi sebesar 2". Bahan pipa PVC tahan tekan, seperti rucika. Sedangkan keran (ball valve) yang dipakai adalah keran tahan karat terbuat dari plastik.

\section{j. Tangki Bahan-Bahan Kimia}

Tangki bahan kimia terdiri dari 2 buah tangki fiberglas dengan volume masing-masing 30 liter. Bahan-bahan kimia adalah ferrosulfat dan PAC. Bahan kimia berfungsi sebagai oksidator.

\subsubsection{Pembangunan Pilot Plant IPAL Industri Kecil Pelapisan Logam}

Lokasi pembangunan pilot plant pengolahan limbah industri pelapisan logam ini 
terletak di kelurahan Cilodong, Kotamadya Depok, Jawa Barat. Dalam pembuatan disain unit pengolahan limbah industri kecil pelapisan logam ada beberapa kriteria disain yang ditetapkan dengan mempertimbangkan kondisi air baku dan kualitas air keluaran. Kontruksi IPAL yang telah terpasang dapat dilihat seperti pada gambar 8.

\subsubsection{Spesifikasi Teknis IPAL}

Disain pilot plant IPAL industri kecil pelapisan logam seperti terlihat pada Gambar 7 dengan spesifikasi teknis sebagai berikut :

$\begin{array}{ll}\text { 1. Tangki Rektor Koagulasi - Flokulasi } \\ \text { Dimensi } & : 450 \mathrm{~cm} \times 150 \mathrm{~cm} \times 225 \mathrm{~cm} \\ \text { Bahan } & : \text { Fiber Reinforced Plastic } \\ & \text { (FRP) } \\ \text { Volume efektif } & : 10 \mathrm{~m}^{3} \\ \text { Inlet Outlet } & : 3 / 4 \text { " } \\ \text { Perlengkapan } & : \text { Valve untuk pengurasan }\end{array}$

\section{Pompa Air Baku Limbah}

$\begin{array}{ll}\text { Tipe } & : \text { Centrifugal Pump CR2-30 } \\ \text { Bahan } & : \text { Stainless Steel } \\ \text { Listrik } & : 500 \text { watt, 220 volt } \\ \text { Tekanan } & : 5 \text { bar }\end{array}$

\section{Pompa Filter}

Tipe

Bahan

: Centrifugal Pump CR2-30

Listrik

: Stainless Steel

Tekanan

500 watt, 220 volt

\section{Filter Multi Media}

$\begin{array}{ll}\text { Kapasitas } & : 1,4-1,8 \mathrm{~m} 3 / \mathrm{jam} \\ \text { Diameter } & : 10 \text { inchi x } 120 \mathrm{~cm} \\ \text { Bahan } & : \text { Polyvinil Chloride (PVC) } \\ \text { Sistem } & : \text { Semi Automatic } \\ & \text { Backwash } \\ \text { Tekanan } & : 3 \text { bar } \\ \text { Media } & : \text { Kerikil, Pasir silika dan } \\ & \text { Mangan Zeolit }\end{array}$

\section{Filter Penukar Kation}

$\begin{array}{ll}\text { Kapasitas } & : 1,4-1,8 \mathrm{~m} 3 / \mathrm{jam} \\ \text { Diameter } & : 10 \text { inchi } \times 150 \mathrm{~cm} \\ \text { Bahan } & : \text { Polyvinil Chloride (PVC) } \\ \text { Sistem } & : \text { Semi Automatic } \\ & \text { Backwash } \\ \text { Tekanan } & : 3 \text { bar } \\ \text { Media } & : \text { Kerikil, Pasir silika dan } \\ & \text { lon exchange }\end{array}$

6. Tangki Bahan Kimia

$\begin{array}{ll}\text { Volume } & : 100 \text { liter } \\ \text { Bahan } & : \text { Fiber Reinforced Plastic } \\ \text { Jumlah } & : 2 \text { unit }\end{array}$

\section{Pompa Dosing}

Tipe

Tekanan

Kapasitas

Jumlah

: Pulsa Feeder 150/100

: 7 bar

: 15 liter

$: 2$ unit

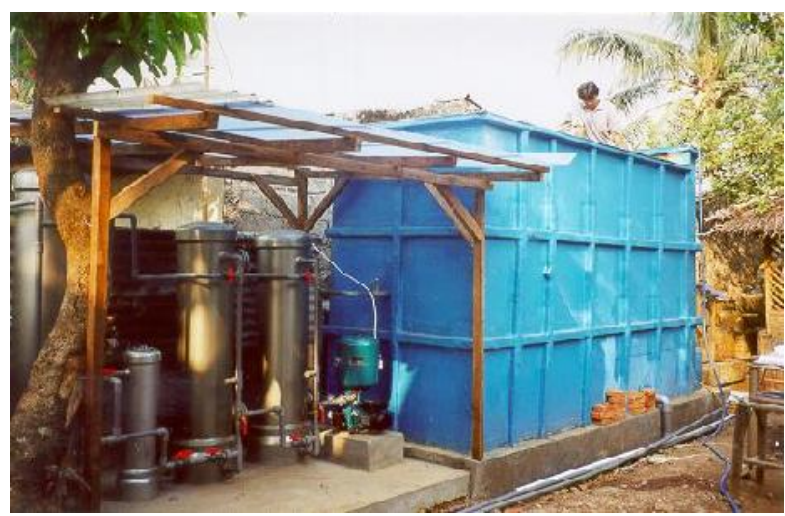

Gambar 8. Kontruksi IPAL pelapisan logam yang telah terpasang

\subsubsection{Uji Coba Di Lapangan}

Berdasarkan hasil pengujian dengan sistem tersebut di atas dengan kondisi operasi :

$$
\begin{array}{ll}
\text { Larutan Kapur } & : 20 \% \\
\text { Larutan Tawas } & : 2 \% \\
\text { Larutan Kaporit } & : 10 \mathrm{mg} / \mathrm{l}
\end{array}
$$

Di dapatkan hasil pengolahan yang cukup baik yakni efisiensi penghilangan Zat Besi ( $\mathrm{Fe}$ ) 95,43 $\%$, efisiensi penghilangan Nickel (Ni) 94,45\%, Efisiensi Penghilangan Zinc (Zn) 66,72 \% dan $\mathrm{pH}$ air menjadi 6,32. Hasil selengkapnya dapat dilihat pada Tabel 1.

Tabel 1 : Hasil Analisa air limbah sebelum dan sesudah pengolahan

\begin{tabular}{|c|c|c|c|c|}
\hline No & $\begin{array}{c}\text { Parameter Air } \\
\text { L:imbah }\end{array}$ & $\begin{array}{c}\text { Air } \\
\text { Limbah } \\
(\mathrm{Mg} / \mathrm{l})\end{array}$ & $\begin{array}{c}\text { Air } \\
\text { Olahan } \\
(\mathrm{Mg} / \mathrm{l})\end{array}$ & $\begin{array}{c}\text { Efisiensi } \\
\text { Pengolahan } \\
(\%)\end{array}$ \\
\hline 1 & $\mathrm{PH}$ & 3,30 & 6,32 & - \\
\hline 2 & Zat Besi (Fe) & 44,64 & 2,04 & 95,43 \\
\hline 3 & Nickel (Ni) & 63,10 & 3,5 & 94,45 \\
\hline 4 & Zinc (Zn) & 31,85 & 10,6 & 66,72 \\
\hline 5 & $\begin{array}{c}\text { Chrom } \\
\text { Hexavalent }\end{array}$ & 0.06 & $<0,05$ & - \\
\hline
\end{tabular}

\section{KESIMPULAN}

Dari uraian diatas dapat diambil beberapa kesimpulan sebagai berikut :

- Kualitas air limbah yang dihasilkan oleh industri pelapisan logam sangat dipengaruhi oleh jenis pelapisnya. Oleh karena itu proses 
pengolahannya harus disesuaikan jenis proses pelapisan logamnya.

- Dengan proses kombinasi pencampur statis (static mixer), koagulasi-flokulasi, saringan multimedia/kerikil, pasir, karbon, mangan zeolit (multimedia filter), saringan karbon aktif (activated carbon filter), dan saringan penukar ion (ion exhange filter) dapat menurunkan secara signifikan pada parameter zinc, ferro, dan parameter lainnya dan hasilnya masuk dalam ambang batas yang diperbolehkan.

- IPAL industri kecil pelapisan logam ini dibangun dengan peralatan dan bahan yang diperoleh dengan mudah didapat di pasaran, sehingga dapat memberikan kemudahan dalam pengerjaan pembangunan dan biaya konstruksi dapat ditekan serendah mungkin.

- Rancangan pilot plant IPAL tersebut dibentuk dengan kompak sehingga pemasangan atau pembangunan dan operasionalnya mudah, serta menggunakan energi yang kecil.

- Dengan telah dibangunnya pilot plant IPAL industri kecil pelapisan logam skala industri kecil, maka diharapkan dapat menjadi percontohan dalam mengatasi permasalahan pencemaran hasil buangan yang ditimbulkan dari kegiatan industri pelapisan logam.

\section{DAFTAR PUSTAKA}

1. Benefiled, L.D., Judkins, J.F., and Weand, B.L., "Process Chemistry For Water And Waste Treatment", Prentice-Hall, Inc., Englewood, 1982.

2. ----, "Gesuidou Shissetsu Sekkei Shisin to Kaisetsu", Nihon Gesuidou Kyoukai, 1984.

3. FAIR, GORDON MASKEW et.al., "Elements Of Water Supply And Waste Water Disposal', John Willey And Sons Inc., 1971.

4. GOUDA T., "Suisitsu Kougaku- Ouyouben", Maruzen kabushiki Kaisha, Tokyo, 1979.

5. METCALF AND EDDY, "Waste Water Engineering", Mc Graw Hill 1978.

6. SUEISHI T., SUMITOMO H., YAMADA K., DAN WADA Y., "Eisei Kougaku " (Sanitary Engineering), Kajima Shuppan Kai, Tokyo, 1987.

7. VIESSMAN W, JR., HAMER M.J., "Water Supply And Polution Control ", Harper \& Row, New York, 1985.

8. HADI SOEWITO, "Ilmu Pengetahuan Logam", PPPG Tek. Bandung, 1992.

9. T.TAUFIK, A. YANI, "Pusat Pelayanan Informasi Teknologi Logam”, BPPT, 1998. 